\title{
Seroprevalence and Virologic Surveillance of Enterovirus 71 and Coxsackievirus A6, United Kingdom, 2006-2017
}

Everlyn Kamau, Dung Nguyen, Cristina Celma, Soile Blomqvist, Peter Horby, Peter Simmonds, Heli Harvala

Enterovirus A71 (EV-A71) and coxsackievirus A6 (CVA6) cause hand, foot and mouth disease (HFMD) and are occasionally linked to severe neurologic complications and large outbreaks worldwide. We estimated EV-A71 and CVA6 seroprevalence using cross-sectional agestratified samples collected in 2006, 2011, and 2017. Seroprevalences of EV-A71 and CVA6 increased from $32 \%$ and $54 \%$ at $6-11$ months to $>75 \%$ by 10 years of age. Antibody titers declined after 20 years, which could indicate infrequent re-exposure in older populations. Age profiles for acquiring infections and mean titers were comparable in the 3 testing years, despite the marked increase in incidence of CVA6-related HFMD from 2010. The uncoupling of changes in disease severity from the infection kinetics of CVA6 as we inferred from the seroprevalence data, rather than incidence of infection over the 11-year study period, provides further evidence for a change in its pathogenicity.

Dnteroviruses within species A are the primary cause of hand, foot and mouth disease (HFMD), mostly affecting infants and young children. HFMD is highly contagious and manifests as a self-limiting illness; it typically includes fever, skin eruptions on hands and feet, and vesicles in the mouth $(1,2)$. In severe disease, patients develop neurologic and systemic complications that can be fatal, including meningoencephalitis, pulmonary edema, and acute flaccid paralysis $(3,4)$.

Enterovirus A71 (EV-A71) is the predominant cause of HFMD outbreaks. In the Asia-Pacific region,

Author affiliations: University of Oxford, Oxford, UK (E. Kamau, D. Nguyen, P. Horby, P. Simmonds); Public Health England, London, UK (C. Celma); National Institute for Health and Welfare, Helsinki, Finland (S. Blomqvist); National Health Service Blood and Transplant, London, UK (H. Harvala); University College London, London, UK ( $\mathrm{H}$. Harvala)

DOI: https://doi.org/10.3201/eid2709.204915 the effects of the virus on public health have been substantial; in Europe these infections are considered mild and often remain undiagnosed (5), although severe neurologic manifestations and small outbreaks have been reported more recently $(6-10)$. EV-A71 is classified into 7 genogroups (A-G) and several subgenogroups (B0-B5, C1-C5) based on the viral protein 1 gene; the appearance of novel EV-A71 genogroups has been associated with large HFMD outbreaks (5).

Coxsackievirus A6 (CVA6) has become another major cause of HFMD since 2008 (11,12). CVA6 infections have often been linked to a febrile atypical form of HFMD, affecting both pediatric and adult populations (13-15). The severity of the clinical manifestations associated with CVA6 infections and the recent increase of HFMD cases associated with EV-A71 and CVA6 in Europe (10) may have originated through the evolution of recombinant forms or changes in pathogenicity of emerging strains $(16,17)$. Alternatively, their clinical prominence may have resulted from an increase in infections in a larger previously unexposed and susceptible populations. To investigate that theory, we determined the age-stratified seroprevalence of EV-A71 and CVA6 in representative cross-sections of the UK population in 2006, 2011, and 2017; we used serotype-specific microneutralization assays and compared our findings with the numbers of infections reported through public health surveillance.

The 2011 timepoint corresponded to the approximate timing of large EV-A71 outbreaks, especially in Vietnam and China $(12,18)$ in addition to emergence of CVA6 infections associated with atypical clinical phenotypes $(11,19)$. Whereas the 2006 timepoint was selected to precede these recorded events and the 2017 to measure population immunity post-CVA6 emergence period, the last timepoint also corresponded to recorded EV-A71 outbreaks in Spain and elsewhere in Europe in $2016(4,7,8)$. Collectively, these selected 
timepoints reflected changed activity of both viruses and hence enabled us to measure their effects on population immunity.

\section{Materials and Methods}

\section{Serum Samples}

We obtained a convenience sample of 1,573 residual serum samples collected in $2006(\mathrm{n}=514), 2011$ ( $\mathrm{n}$ $=498)$, and $2017(\mathrm{n}=561)$ from the seroepidemiology unit archive collection of Public Health England (PHE; Manchester, UK). This archive is an opportunistic collection of residual clinical samples from laboratories throughout England. Case-patients were divided into 7 age groups: $<6$ months, 6-11 months, 1-5 years, 6-10 years, 11-20 years, $21-40$ years, and $>40$ years. We aimed to obtain 100 samples from each group (Appendix, https://wwwnc.cdc.gov/EID/ article/27/9/20-4915-App1.pdf). We anonymized all samples and unlinked any patient identifying information; we retained age, sex, date of collection, sample type, and contributing laboratory information.

\section{Virus Strains}

We obtained 2 CVA6 strains isolated in Finland in 2008 and 2016 from the National Institute for Health and Welfare (Helsinki, Finland). The CVA6/2008 isolate was obtained during a HFMD outbreak in Finland (20), and the CVA6/2016 isolate was a contemporary clinical strain. We used the EV-A71 genogroup B4 strain isolated in Singapore (5865/ SIN/000009). We propagated EV-A71 viruses in a rhabdomyosarcoma cell line obtained from the American Type Culture Collection. We propagated CVA6 viruses in TE32 or 130T cells obtained from the UK National Institute for Biologic Standards and Control. We determined the 50\% tissue culture infective dose $\left(\mathrm{TCID}_{50}\right)$ of virus stocks by means of endpoint dilution using the Reed and Muench method: in a 96-well format, 8 replicates of a 10-fold serial dilution were incubated with cells in Dulbecco minimum essential medium (DMEM; Sigma-Aldrich, https://www.sigmaaldrich.com) containing $2 \% \mathrm{vol} / \mathrm{vol}$ fetal bovine serum (FBS; Sigma-Aldrich) and penicillin/streptomycin (10,000 U/mL; SigmaAldrich) at $37^{\circ} \mathrm{C}$ in $5 \% \mathrm{CO}_{2}$ for $4-5$ days.

\section{Neutralization Assays}

The microneutralization assay was performed as previously described (21) (Appendix). In brief, we inactivated serum samples for $3 \mathrm{~min}$ at $56^{\circ} \mathrm{C}$, and then diluted 2-fold serially in 2\% DMEM-FBS from 1:8 to 1:1,024. We mixed $50 \mu \mathrm{L}$ of diluted samples and 100
TCID $_{50}$ of virus stock diluted in $50 \mu \mathrm{L}$ in 96-well microplates and incubated at $37^{\circ} \mathrm{C}$ for 1 hour. We added $100 \mu \mathrm{L}$ of cell suspension containing average of 20,000 rhabdomyosarcoma cells in 10\% DMEM-FBS for EVA71 assays and average of 20,000 TE32 cells in 5\% DMEM-FBS for CVA6 assays. We observed cytopathic effect in an inverted microscope after incubating at $37^{\circ} \mathrm{C}$ in $5 \% \mathrm{CO}_{2}$ for $4-5$ days. We used pooled adult serum with known neutralizing antibody titer (nAb; $13 / 328$, obtained from the UK National Institute for Biologic Standards and Control) as a positive control and inactivated horse serum (obtained from American Type Culture Collection) as negative control. We included a virus control and an uninfected cell control for each batch of tests. We tested each sample in duplicate and calculated results as their geometric mean titers (GMT).

To determine the optimal strain for the CVA6 neutralizing assay, we compared titers of 36 serum samples collected in 2006 against the 2 CVA6 clinical isolates. We selected 18 samples each for the 1-5-year (representing serologic responses acquired during 2001-2006) and >40-year (representing serologic responses acquired substantially before 2006) age groups. For the 1-5-year age group, 16/18 samples tested were seropositive for the CVA6/2008 and 17/18 samples tested were seropositive for CVA6/2016 isolates. All 18 samples tested from the $>40$-year age group were seropositive for both CVA6 isolates. GMT to both CVA6 isolates were comparable between the 1-5-year and $>40$-year age groups (Appendix, Figure 1). Samples collected from the $>40$ year age group in 2006 had proportionately higher $\mathrm{nAb}$ against the CVA6/2008 isolate $(\mathrm{p}=0.008$ by paired Wilcoxon signed rank test). Because the differences in GMT between the CVA6 isolates were minor, we selected the more contemporary CVA6/2016 strain for the assay used in this study.

We reported the neutralizing titer as the reciprocal titer of serum dilutions that inhibited $50 \%$ virus growth. For both EV-A71 and CVA6, samples with $\mathrm{nAb}$ titers of $\geq 1: 8$ were considered seropositive as previously reported $(22,23)$. For GMT calculations, we excluded titers $<1: 8$; we assigned a value of 2,048 to titers $\geq 1: 1,024$. We classified GMT values as low $(<1: 64)$, moderate (1:64-1:256), and high $(\geq 1: 512)$.

\section{Virological Surveillance Data}

We collected information on enterovirus-positive samples submitted for typing to the PHE Enteric Virus Unit (London, UK), during 2006-2017. Local diagnostic laboratories in England and Wales were asked to forward samples in which EV RNA has been detected 
for typing, for the purposes of national enhanced enterovirus surveillance. Data collected included a total number of enterovirus-positive samples submitted for typing and the number identified as EV-A71 or CVA6 per month, patient age group, and sample type.

We used these data to compare the prevalence of infections estimated from serologic data with EV-A71and CVA6-associated infections reported through this voluntary enhanced enterovirus surveillance.

\section{Statistical Analysis}

We compared rates of seropositivity in different groups using $\chi^{2}$ or Fisher exact test, with Bonferroni adjustment for multiple comparison. We compared age-stratified GMTs between the serum collection time points using the Mann-Whitney $U$ or Kruskal-Wallis test with Dunn's post hoc analysis. We calculated $95 \%$ CIs of the seroprevalence rates according to the Wilson method (http:/ / vassarstats. net/prop1.html) and considered $\mathrm{p}<0.05$ statistically significant. We computed all the statistical analyses in R (https:/ / www.r-project.org).

\section{Results}

Enterovirus Reporting in the United Kingdom, 2006-2017 We identified 402 EV-A71-positive and 1,519 CVA6positive samples from 20,221 enterovirus-positive samples referred to PHE for typing (Figure 1, panel A). Over the study period, the numbers of enterovirus-positive samples referred for typing increased substantially from 189 in 2006 to 1,479 in 2017. At the same time, the proportion of samples typed as CVA6 increased sharply, from $\approx 1 \%$ in $2007-2008$ to $10 \%$ in
2016-2017, and the proportion of samples typed as EV-A71 decreased.

Most EV-A71 infections were reported in even years; $\approx 10 \%$ of all enterovirus-positive samples were identified as EV-A71 in 2006, 2008, and 2010, whereas this proportion has remained at $\approx 3 \%$ since 2012 . The peak months for EV-A71 detections were JulyAugust and for CVA6 detections were October-December. The highest monthly detections were 20 of EV-A71 in July 2013 and 74 of CVA6 in October 2017 (Figure 1, panel B).

EV-A71 infections were mostly identified in feces (122/381, 32\%; data not available for 21 samples), followed by cerebrospinal fluid (CSF) $(100 / 381,26.2 \%)$, respiratory specimens $(46 / 381,12.1 \%)$, vesicle or skin swabs $(21 / 381,5.5 \%)$, and blood (24/381, 6.3\%) (Table). Consistent with its association with HFMD in the UK, CVA6 was mostly detected in vesicle or skin swabs (759/1,033, 73.5\%; data not available for 486 samples), followed by respiratory specimens $(136 / 1,033,13.2 \%)$, feces $(84 / 1,033,8.1 \%)$, CSF $(44 / 1,033,4.3 \%)$, and blood $(42 / 1,033,4.1 \%)$.

Patient age data were available for 9,636/20,211 total samples. Age data were available for 381/402 EV-A71 samples, and for 1,029/1,519 CVA6 samples. Most enterovirus-positive samples were obtained from young children $<3$ months of age $(3,730 / 9,636$, $39 \%)$, or young adults $(2,309 / 9,636,24 \%)$ (Figure 2, panel A). EV-A71 detections were highest in infants $<3$ months (222/381, 58\%), whereas 58/381 (15\%) were identified in children 4-12 months of age and $63 / 381(17 \%)$ in children 1-5 years of age. CVA6 infections were diagnosed most often in older children $1-5$ years of age $(52 \%, 537 / 1,029)$, followed by
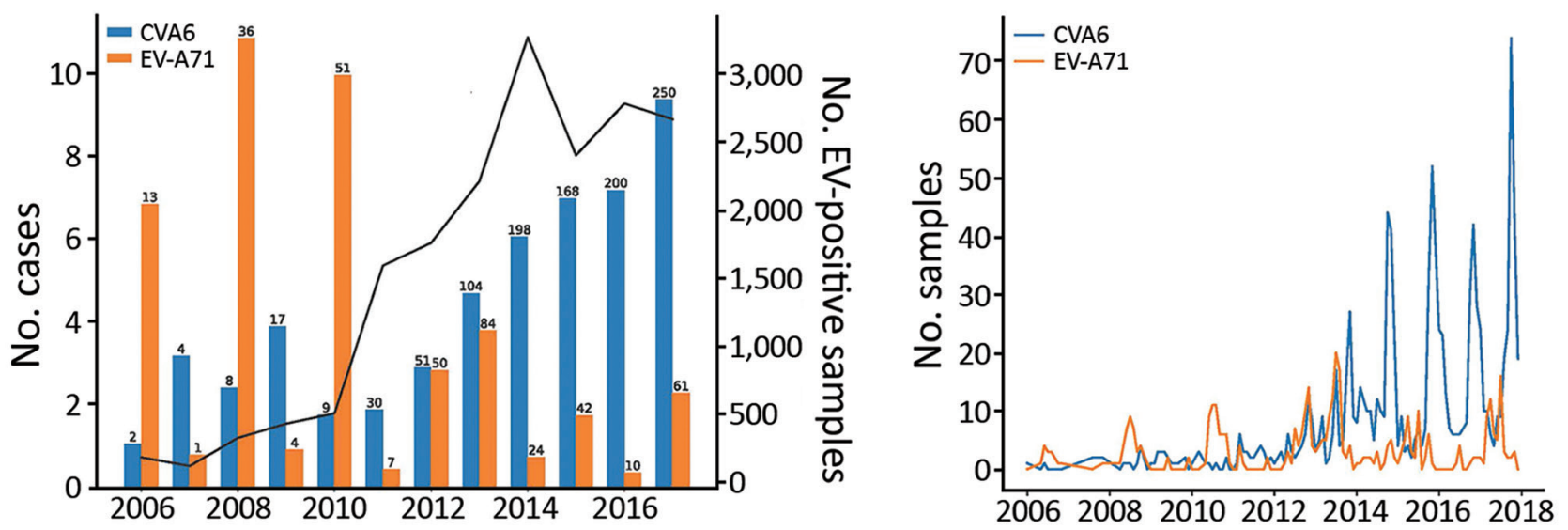

Figure 1. EV-A71 and CVA6 identified in enterovirus-positive samples referred to Public Health England from laboratories throughout England, UK, by year, 2006-2017. A) Percentage of samples typed as EV-A71 and CVA6 in each referral year (total no. cases above each bar). Solid black line indicates number of samples referred for virus typing. B) Distribution of EV-A71 $(n=381)$ and CVA6 $(n=$ 1,033) clinical detections in England, using monthly totals for the period 2006-2017. CVA6, coxsackievirus A6; EV, enterovirus; EV-A71, enterovirus A71. 
Table. EV-A71- and CVA6-positive samples submitted to the Public Health England Enteric Virus Reference Department, United Kingdom, 2006-2017*

\begin{tabular}{lcccccc}
\hline Virus & Blood & CSF & Gastrointestinal & Respiratory & Skin & Tissue \\
\hline EV-A71 & $24(6.3)$ & $100(26.2)$ & $122(32)$ & $46(12.1)$ & $21(5.5)$ & $25(6.6)$ \\
CVA6 & $42(4.1)$ & $44(4.3)$ & $84(8.1)$ & $136(13.2)$ & $759(73.4)$ & $19(1.8)$ \\
\hline
\end{tabular}

children 4-12 months of age $(23 \%, 239 / 1,029)$. In contrast, a small number of CVA6 infections were reported in infants $<3$ months of age $(56 / 1,029,5 \%)$. We observed no change in EV-A71 or CVA6 detection by age group for 2006-2017 (Figure 2, panels B and C).

\section{Seroprevalence of EV-A71}

The overall seropositivity rate of EV-A71 was 74\% (95\% CI 71.8\%-76.2\%). The seropositivity rates for the 3 timepoints were comparable at 71\% (95\% CI 66.8\%$75.0 \%$ ) in $2006,73 \%$ (95\% CI $69.1 \%-77.0 \%$ ) in 2011 , and $77 \%$ (95\% CI $73.8 \%-80.9 \%)$ in 2017. Age-specific seroprevalence of EV-A71 nAb in each timepoint were lowest in children 6-11 months of age and gradually increased with age category $\left(\mathrm{p}<0.001\right.$ by $\chi^{2}$ test for trend) (Figure 3; Appendix Table 1). The seropositivity rate for the $>40$-year age group increased from $77 \%$ in 2011 to $91 \%$ in 2017 ( $p=0.003$ Fisher exact test).

The proportion of samples with moderate (64256) and high $(\geq 512)$ nAb titers increased with age from 1-20 years but decreased thereafter; most (>85\%) samples from adults $>20$ years had titers $\leq 256$ (Figure $3)$. For example, in 2006, the proportion of patients with high titers decreased from $30 \%$ in the 11-20-year age group to $6.7 \%$ in the $21-40$-year age group and to $3.8 \%$ in the $>40$-year age group. We observed a similar trend of declining titers through 2011, in which the proportion of patients with high titers dropped by age group, from $12 \%$ (11-20 years) to $9 \%$ (21-40 years) to $2 \%$ (>40 years), and through 2017 , when titers drop from $19 \%$ (11-20 years) to 11\% (21-40 years) to $5 \%$ (>40 years).

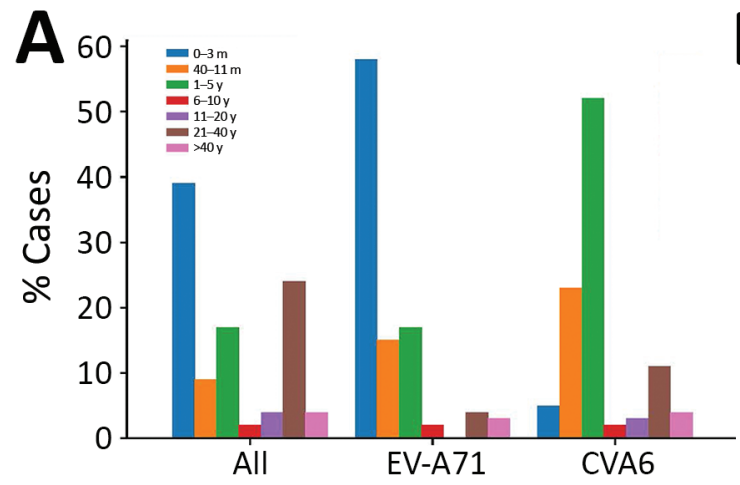

The seropositive samples from infants ( $<6$ months of age) in 2006 had a GMT 5-fold higher than the same age group in 2017, whereas those from children 6-11 months of age in 2006 had a geometric mean titer 3.6fold higher than the same age group in 2017. Similarly, the samples from children 1-5 years of age in 2011 had a GMT 5.5-fold higher than in 2017 (Appendix, Appendix Table 1). Significant increases in titers of seropositive samples were found among children $<6$ months ( $\mathrm{p}=0.014$ by Kruskal-Wallis test) and $1-5$ years of age $(p=0.0026)$ and also among patients aged 11-20 years of age $(\mathrm{p}=0.0067)$ (Appendix, Appendix Figure).

\section{Seroprevalence of CVA6}

The seropositivity for CVA6 was $80 \%$ (95\% CI 78.282.3 ) overall and $82 \%$ (95\% CI 78.7-85.3) for 2006, 78\% (95\% CI 74-81.8) for 2011, and 80\% (76.7-83.3) for 2017; seropositivity similarly increased with increasing age group ( $\mathrm{p}<0.001$ by $\chi^{2}$ test for trend) (Figure 3; Appendix, Appendix Table 2). The seropositivity rates were comparable across age groups ( $p>0.05$ by Fisher exact test). We observed significant differences in CVA6 antibody titers among seropositive samples from children $<6$ months of age $(p<0.001$ by Kruskal-Wallis test), $1-5$ years of age $(p=0.005)$, and $6-10$ years of age $(p<0.001)$. Neutralizing antibody titers were significantly lower in 2011 for seropositive samples (titer $\geq 8$ ) in the $21-40$-year and $>40$-year age groups (Appendix, Appendix Figure 2).

The proportion of infants $<6$ months of age with titers $\geq 64$ was significantly higher in 2006 (75\%) than

Figure 2. EV-A71 and CVA6 identified in enterovirus-positive samples referred to Public Health England from laboratories throughout England, UK, by age, 2006-2017. A) Percentage of all enterovirus-positive samples, by age group. B, C) EV-A71 (B) and CVA6 (C) detection by age group and by year of sampling. CVA6, coxsackievirus A6; EV-A71, enterovirus A71. 

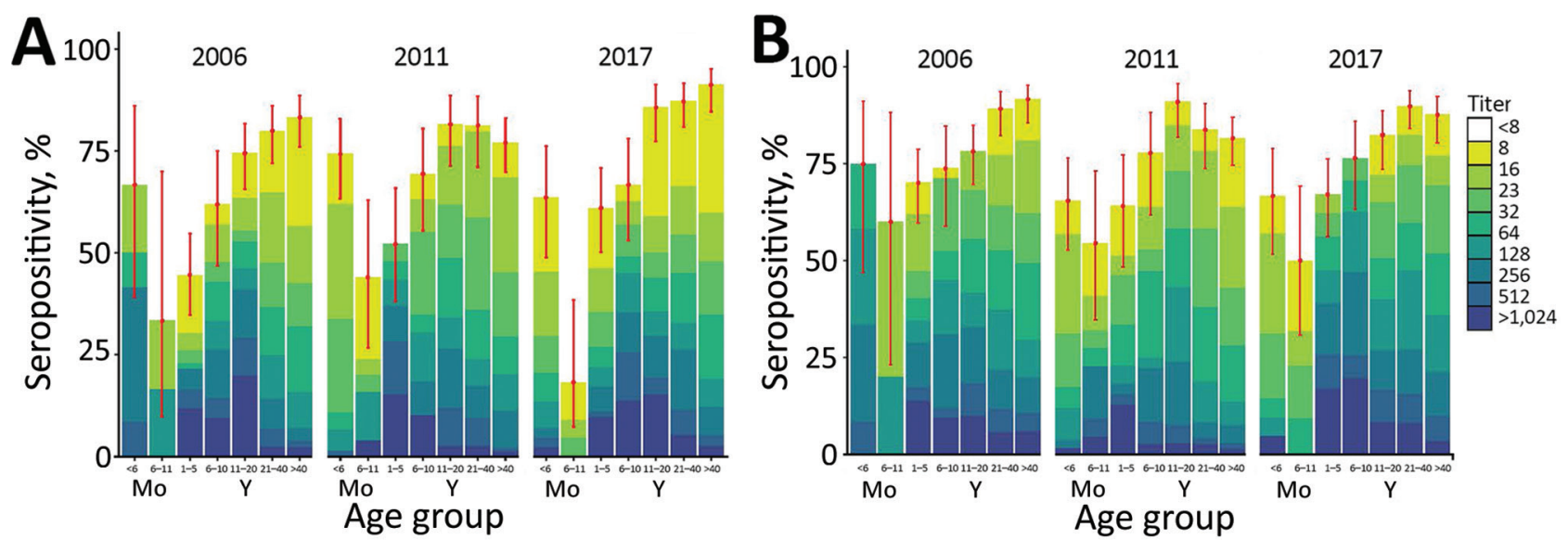

Figure 3. EV-A71(A) and CVA6 (B)seroprevalence in England, UK, in 2006, 2011, and 2017, by age group. Results are expressed as percentage of samples displaying neutralizing antibody titers $<8$ to $\geq 1,024$ (colored bars). Red dots represent point estimates of the seropositive proportion; error bars indicate $95 \% \mathrm{Cl}$. Samples were scored seropositive if neutralization was achieved at serum dilution of $\geq 1: 8$. CVA6, coxsackievirus A6; EV-A71, enterovirus A71.

in $2011(17 \%)$ and $2017(14 \%)$, whereas the proportion of adults $>40$ years of age with moderate titers was significantly lower in $2011(27.8 \%)$ than in 2006 $(49.2 \%)$ and $2017(51.7 \%) \quad(p<0.001$ by Fisher exact test) (Figure 3). Geometric mean titers were highest in children 1-10 years of age in 2017 and $>5$-fold higher in 2006 for the <6-month-olds (Appendix Table 2).

\section{Discussion}

Seroepidemiology findings in this study showed that EV-A71 and CVA6 infections were highly prevalent among children and adults in the United Kingdom. From the minimum values in the 6-11-month age group after the decline of maternally conferred immunity $(24,25)$, we determined that EV-A71 and CVA6 neutralizing antibody detection frequencies and titers increased steadily with age, which indicates ongoing exposure and infection throughout childhood. EV-A71 seropositivity rates observed in the United Kingdom were comparable to those observed among preschool children $<6$ years of age $(63.4 \%)$ in Germany (26) and in children $\leq 5$ years of age in the Netherlands (27). EV-A71 seroprevalence in adults $(>75 \%)$ was comparable for the United Kingdom, the Netherlands, and Germany.

The number of persons with high titers of EV-A71 neutralizing antibodies declined with age; this finding is consistent with previous seroepidemiological studies, including the report of high EV-A71 antibody titers in the 10-14-year age group in Germany (28), and comparable to the peak titers recorded in the 11-20year age group in our study. These findings indicate that EV-A71 primarily circulates in and infects children, and the subsequent decline in titers but not fre- quencies of seropositivity indicates that re-exposure in the older population is uncommon (28-30). The decline in titers may also reflect the differences between acute serologic responses post-infection in the younger population and homeostatic antibody levels in the older population that become established years after infection (30). Related to this decline, the $>4$-fold attrition in mean EV-A71 neutralizing antibody titers in the 21-40-year age group (Appendix Table 1) may also create the low mean titers of maternally derived antibodies observed in children $<6$ months of age. This finding may underpin the high incidence of EVA71 diagnosis reported in the $0-3$-month age group when infants are most susceptible to severe infection outcomes (Figure 3). Of note, the largest share (39\%) of enterovirus-positive samples were obtained from this age group, which might attest to infants' vulnerability and higher likelihood of sampling.

The global emergence of CVA6 since 2008 has been linked to an increase in pathogenicity of CVA6 around 2010 (31), becoming another major causative agent for HFMD in several countries worldwide (23). This change was reflected in the number of atypical HFMD caused by CVA6 in Scotland in 2014 (19) and also in the increasing numbers of reported CVA6 infections in our study (Figure 1). Our seroprevalence data show that CVA6 circulated widely before the emergence of atypical HFMD in 2008 (25); seroprevalence approached $90 \%$ in adults $>40$ years of age as recorded in 2006 (Figure 3). This observation discounts the idea that the increased incidence of CVA6-associated HFMD simply reflects a change in its infection incidence and the existence of a widely susceptible population. 
Comparing the 2 serotypes, CVA6 seroprevalence was higher than EV-A71 seroprevalence in younger children (1-10 years) in each study year (Figure 3; Appendix Tables 1, 2). However, this difference was not reflected in the peak age group for CVA6 infections (1-5 years) (Figure 2), which contrasts with the predominance of EV-A71 infections recorded in neonates and infants. CVA6 infections were predominantly detected in skin vesicle fluids (Table; Appendix), which would primarily be associated with HFMD manifestations (32-34).

Over the study period, the number of samples referred to PHE substantially increased (Figure 1), but rather than indicating more enterovirus-associated disease, this finding is more likely a reflection of improvements in detection through exclusive introduction of PCR in the clinical laboratories (35). Diagnostic practices in general, and for enteroviruses in particular, have changed over time in England and Wales as previously described (35). The use of PCR has increased rapidly, from $36 \%$ in 2000 to $45 \%$ in 2011, and probably approached $100 \%$ in 2015 , replacing the slow and laborious virus culture entirely.

Changes in clinical practice or diagnostic procedures, such as the threshold for investigating and hospitalizing patients with suspected viral infections, or performing lumbar puncture (35), may have further influenced the number of samples submitted to PHE. Controlled cohort-based surveillance studies are required to better infer $\mathrm{EV}$ incidence.

A limitation of this study is that we based our inferences of incidences of EV-A71 and CVA6 infections on referral of clinical samples for typing at PHE. The much lower numbers of EV-A71-positive samples identified from older children and adults (Figure 2) at a time when seroprevalence was increasing (Figure 3) is indicative of subclinical infections or benign disease in these age groups. Differences in clinical practices could have also influenced the number of samples obtained and referred from older children and adults to PHE. For instance, CSF samples are more likely to be obtained for enterovirus testing from these patients who had any neurologic symptoms, compared with throat, fecal, or rectal swab specimens from which the viral loads would be higher and virus excretion prolonged $(36,37)$. In addition, delayed lumbar puncture also reduces the likelihood of a positive pathogen detection. Atypical and varying clinical manifestations, especially in older adults, and the absence of CSF pleocytosis may also impede the timely diagnosis of enteroviral infections and consequently reduce the number of samples found to be positive and referred to PHE.
We used a convenience sample of residual serum samples from diagnostic laboratories throughout England. Although we attempted to include equal sample sizes for all ages, the serosurvey was not powered to provide precise seroprevalence estimates for certain age groups. The volume of available specimens, particularly for the younger age groups, was insufficient, thus limiting the number of samples tested and generalization of our results to the larger pediatric population. Convenience samples are also prone to chance variations in sampling between geographic regions. Lack of additional information on participants' risk factors for exposure was another limitation.

In summary, we provide an analysis of age-stratified seroprevalence of EV-A71 and CVA6 in the UK population. Prevalence of infection by both viruses inferred from age-related changes in seroprevalence varied little over the 11-year study period despite the emergence of CVA6-associated HFMD in 2010, implying changes in CVA6 pathogenicity rather than changes in population susceptibility to severe infection outcomes. This study will enable a more detailed understanding of population susceptibility, the emergence of enterovirus serotypes, and potential changes in serotype pathogenicity and transmissibility.

\section{Acknowledgments}

We thank the personnel at the National Polio Laboratory, THL, Helsinki, Finland, for culturing the virus strains. We thank Simon Tonge and colleagues at the Vaccine Evaluation Unit, Public Health England, Manchester, for provision of archive samples.

\section{About the Author}

Ms. Kamau is a doctoral candidate at the University of Oxford, UK. Her primary research interest is epidemiology of infectious diseases.

\section{References}

1. Aswathyraj S, Arunkumar G, Alidjinou EK, Hober D. Hand, foot and mouth disease (HFMD): emerging epidemiology and the need for a vaccine strategy. Med Microbiol Immunol (Berl). 2016;205:397-407. https://doi.org/10.1007/ s00430-016-0465-y

2. Klein M, Chong $\mathrm{P}$. Is a multivalent hand, foot, and mouth disease vaccine feasible? Hum Vaccin Immunother. 2015;11:2688-704. https://doi.org/10.1080/21645515. 2015.1049780

3. Chang LY, Lin HY, Gau SS, Lu CY, Hsia SH, Huang YC, et al. Enterovirus A71 neurologic complications and longterm sequelae. J Biomed Sci. 2019;26:57. https:/ / doi.org/ 10.1186/s12929-019-0552-7

4. Karrasch M, Fischer E, Scholten M, Sauerbrei A, Henke A, Renz DM, et al. A severe pediatric infection with a novel 
enterovirus A71 strain, Thuringia, Germany. J Clin Virol. 2016;84:90-5. https:// doi.org/10.1016/j.jcv.2016.09.007

5. Hassel C, Mirand A, Lukashev A, TerletskaiaLadwig E, Farkas A, Schuffenecker I, et al. Transmission patterns of human enterovirus 71 to, from, and among European countries, 2003 to 2013. Euro Surveill. 2015;20:30005. https://doi.org/10.2807/1560-7917.ES.2015.20.34.30005

6. Ngangas ST, Lukashev A, Jugie G, Ivanova O, Mansuy JM, Mengelle C, et al. Multirecombinant enterovirus A71 subgenogroup $\mathrm{C} 1$ isolates associated with neurologic disease, France, 2016-2017. Emerg Infect Dis. 2019;25:1204-8. https://doi.org/10.3201/eid2506.181460

7. Casas-Alba D, de Sevilla MF, Valero-Rello A, Fortuny C, García-García JJ, Ortez C, et al. Outbreak of brainstem encephalitis associated with enterovirus-A71 in Catalonia, Spain (2016): a clinical observational study in a children's reference centre in Catalonia. Clin Microbiol Infect. 2017;23:874-81. https:/ / doi.org/10.1016/j.cmi.2017.03.016

8. Antona D, Kossorotoff M, Schuffenecker I, Mirand A, Leruez-Ville M, Bassi C, et al. Severe paediatric conditions linked with EV-A71 and EV-D68, France, May to October 2016. Euro Surveill. 2016;21. https:/ / doi.org/10.2807/ 1560-7917.ES.2016.21.46.30402

9. Solomon T, Lewthwaite P, Perera D, Cardosa MJ, McMinn P, Ooi MH. Virology, epidemiology, pathogenesis, and control of enterovirus 71. Lancet Infect Dis. 2010;10:778-90. https://doi.org/10.1016/S1473-3099(10)70194-8

10. Bubba L, Broberg EK, Jasir A, Simmonds P, Harvala H, et al.; Enterovirus study collaborators. Circulation of non-polio enteroviruses in $24 \mathrm{EU}$ and EEA countries between 2015 and 2017: a retrospective surveillance study. Lancet Infect Dis. 2020;20:350-61. https:/ / doi.org/10.1016/ S1473-3099(19)30566-3

11. Bian L, Wang Y, Yao X, Mao Q, Xu M, Liang Z. Coxsackievirus A6: a new emerging pathogen causing hand, foot and mouth disease outbreaks worldwide. Expert Rev Anti Infect Ther. 2015;13:1061-71. https:/ / doi.org/10.1586/ 14787210.2015.1058156

12. Anh NT, Nhu LNT, Van HMT, Hong NTT, Thanh TT, Hang VTT, et al. Emerging coxsackievirus A6 causing hand, foot and mouth disease, Vietnam. Emerg Infect Dis. 2018;24:654-62. https:// doi.org/10.3201/eid2404.171298

13. Mathes EF, Oza V, Frieden IJ, Cordoro KM, Yagi S, Howard R, et al. "Eczema coxsackium" and unusual cutaneous findings in an enterovirus outbreak. Pediatrics. 2013;132:e149-57. https:/ / doi.org/10.1542/ peds.2012-3175

14. Feder HM Jr, Bennett N, Modlin JF. Atypical hand, foot and mouth disease: a vesiculobullous eruption caused by coxsackie virus A6. Lancet Infect Dis. 2014;14:83-6. https:/ / doi.org/10.1016/S1473-3099(13)70264-0

15. Harris PNA, Wang AD, Yin M, Lee CK, Archuleta S. Atypical hand, foot, and mouth disease: eczema coxsackium can also occur in adults. Lancet Infect Dis. 2014;14:1043. https:/ / doi.org/10.1016/S1473-3099(14)70976-4

16. Chen YJ, Chang SC, Tsao KC, Shih SR, Yang SL, Lin TY, et al. Comparative genomic analysis of coxsackievirus A6 strains of different clinical disease entities. PLoS One. 2012;7:e52432. https:// doi.org/10.1371/journal.pone.0052432

17. Gaunt E, Harvala H, Österback R, Sreenu VB, Thomson E, Waris $\mathrm{M}$, et al. Genetic characterization of human coxsackievirus A6 variants associated with atypical hand, foot and mouth disease: a potential role of recombination in emergence and pathogenicity. J Gen Virol. 2015;96:1067-79. https:/ / doi.org/10.1099/vir.0.000062

18. Xing W, Liao Q, Viboud C, Zhang J, Sun J, Wu JT, et al. Hand, foot and mouth disease in China, 2008-12: an epidemiological study. Lancet Infect Dis. 2014;14:308-18. https:/ / doi.org/10.1016/S1473-3099(13)70342-6

19. Sinclair C, Gaunt E, Simmonds P, Broomfield D, Nwafor N, Wellington L, et al. Atypical hand, foot and mouth disease associated with coxsackievirus A6 infection, Edinburgh, United Kingdom, January to February 2014. Euro Surveill. 2014;19:20745. https:/ / doi.org/10.2807/ 1560-7917.ES2014.19.12.20745

20. Österback R, Vuorinen T, Linna M, Susi P, Hyypiä T, Waris M. Coxsackievirus A6 and hand, foot and mouth disease, Finland. Emerg Infect Dis. 2009;15:1485-8. https://doi.org/10.3201/eid1509.090438

21. Kamau E, Harvala H, Blomqvist S, Nguyen D, Horby P, Pebody R, et al. Increase in enterovirus D68 infections in young children, United Kingdom, 2006-2016. Emerg Infect Dis. 2019;25:1200-3. https://doi.org/10.3201/eid2506.181759

22. Nguyet LA, Thanh TT, Nhan LNT, Hong NTT, Nhu LNT, Van HMT, et al. Neutralizing antibodies against enteroviruses in patients with hand, foot and mouth disease. Emerg Infect Dis. 2020;26:298-306. https:/ / doi.org/10.3201/ eid2602.190721

23. Ang LW, Tay J, Phoon MC, Hsu JP, Cutter J, James L, et al. Seroepidemiology of coxsackievirus A6, coxsackievirus A16, and enterovirus 71 infections among children and adolescents in Singapore, 2008-2010. PLoS One. 2015; 10:e0127999. https:/ / doi.org/10.1371/journal.pone.0127999

24. Yang B, Wu P, Wu JT, Lau EH, Leung GM, Yu H, et al. Seroprevalence of enterovirus 71 antibody among children in China. Pediatr Infect Dis J. 2015;34:1399-406. https://doi.org/10.1097/INF.0000000000000900

25. Luo ST, Chiang PS, Chao AS, Liou GY, Lin R, Lin TY, et al. Enterovirus 71 maternal antibodies in infants, Taiwan. Emerg Infect Dis. 2009;15:581-4. https:/ / doi.org/10.3201/1504.081550

26. Diedrich S, Weinbrecht A, Schreier E. Seroprevalence and molecular epidemiology of enterovirus 71 in Germany. Arch Virol. 2009;154:1139-42. https://doi.org/10.1007/ s00705-009-0413-x

27. van der Sanden SM, Koen G, van Eijk H, Koekkoek SM, de Jong MD, Wolthers KC. Prediction of protection against Asian enterovirus 71 outbreak strains by cross-neutralizing capacity of serum from Dutch donors, the Netherlands. Emerg Infect Dis. 2016;22:1562-9. https:/ / doi.org/10.3201/ eid2209.151579

28. Rabenau HF, Richter M, Doerr HW. Hand, foot and mouth disease: seroprevalence of coxsackie A16 and enterovirus 71 in Germany. Med Microbiol Immunol (Berl). 2010;199:45-51. https:/ / doi.org/10.1007/s00430-009-0133-6

29. Ooi EE, Phoon MC, Ishak B, Chan SH. Seroepidemiology of human enterovirus 71, Singapore. Emerg Infect Dis. 2002;8:995-7. https:/ / doi.org/10.3201/eid0809.010397

30. Tran CB, Nguyen HT, Phan HT, Tran NV, Wills B, Farrar J, et al. The seroprevalence and seroincidence of enterovirus71 infection in infants and children in Ho Chi Minh City, Viet Nam. PLoS One. 2011;6:e21116. https:// doi.org/10.1371/ journal.pone.0021116

31. Pons-Salort M, Grassly NC. Serotype-specific immunity explains the incidence of diseases caused by human enteroviruses. Science. 2018;361:800-3. https://doi.org/ $10.1126 /$ science.aat6777

32. Xing W, Liao Q, Viboud C, Zhang J, Sun J, Wu JT, et al. Hand, foot, and mouth disease in China, 2008-12: an epidemiological study. Lancet Infect Dis. 2014;14:308-18. https:/ / doi.org/10.1016/S1473-3099(13)70342-6

33. Ju Y, Tan Z, Huang H, Chen M, Tan Y, Zhang C, et al. Clinical and epidemiological characteristics of coxsackievirus A6- and enterovirus 71-associated clinical stage 2 and 3 
severe hand, foot and mouth disease in Guangxi, Southern China, 2017. J Infect. 2020;80:121-42. https://doi.org/10.1016/j.jinf.2019.09.021

34. Chen S-C, Chang H-L, Yan T-R, Cheng Y-T, Chen K-T. An eight-year study of epidemiologic features of enterovirus 71 infection in Taiwan. Am J Trop Med Hyg. 2007;77:188-91.

35. Kadambari S, Bukasa A, Okike IO, Pebody R, Brown D, Gallimore C, et al. Enterovirus infections in England and Wales, 2000-2011: the impact of increased molecular diagnostics. Clin Microbiol Infect. 2014;20:1289-96. https://doi.org/10.1111/1469-0691.12753

36. Kupila L, Vuorinen T, Vainionpäā R, Marttila RJ, Kotilainen P. Diagnosis of enteroviral meningitis by use of polymerase chain reaction of cerebrospinal fluid, stool, and serum specimens. Clin Infect Dis. 2005;40:982-7. https://doi.org/10.1086/428581

37. Harvala H, Broberg E, Benschop K, Berginc N, Ladhani S, Susi P, et al. Recommendations for enterovirus diagnostics and characterization within and beyond Europe. J Clin Virol. 2018;101:11-7. https:/ / doi.org/10.1016/ j.jcv.2018.01.008

Address for correspondence: Everlyn Kamau, Peter Medawar Building for Pathogen Research, South Parks Road, Oxford OX13SY, UK; email: everlyn.kamau@ndm.ox.ac.uk

\section{April 2021}

\section{High-Consequence Pathogens}

- Blastomycosis Surveillance in 5 States, United States, 1987-2018

- Reemergence of Human Monkeypox and Declining Population Immunity in the Context of Urbanization, Nigeria, 2017-2020

- Animal Reservoirs and Hosts for Emerging Alphacoronavirsuses and Betacoronaviruses

- Difficulties in Differentiating Coronaviruses from Subcellular Structures in Human Tissues by Electron Microscopy

- Characteristics of SARS-CoV-2 Transmission among Meat Processing Workers in Nebraska, USA, and Effectiveness of Risk Mitigation Measures

- Systematic Review of Reported HIV Outbreaks, Pakistan, 2000-2019

- Infections with Tickborne Pathogens after Tick Bite, Austria, 2015-2018

- Emergence of Burkholderia pseudomallei Sequence Type 562 Northern Australia

- Histopathological Characterization of Cases of Spontaneous Fatal Feline Severe Fever with Thrombocytopenia Syndrome, Japan

- COVID-19-Associated Pulmonary Aspergillosis, March-August 2020

- Experimental SARS-CoV-2 Infection of Bank Voles

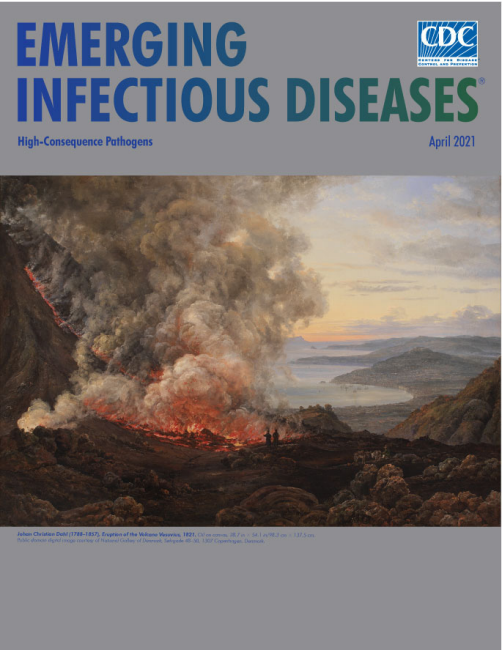

- Genomic Surveillance of a Globally Circulating Distinct Group W Clonal Complex 11 Meningococcal Variant, New Zealand, 2013-2018

- Dynamic Public Perceptions of the Coronavirus Disease Crisis, the Netherlands, 2020

- Evolution of Sequence Type 4821 Clonal Complex Hyperinvasive and Quinolone-Resistant Meningococci

- Epidemiologic and Genomic Reidentification of Yaws, Liberia

- Analysis of Asymptomatic and Presymptomatic Transmission in SARS-CoV-2 Outbreak, Germany, 2020
- Sexual Contact as Risk Factor for Campylobacter Infection

- Venezuelan Equine Encephalitis Complex Alphavirus in Bats, French Guiana

- Stability of SARS-CoV-2 RNA in Nonsupplemented Saliva

- Increased SARS-Cov-2 Testing Capacity with Pooled Saliva Samples

- Persistence of SARS-CoV-2 $\mathrm{N}$-Antibody Response in Healthcare Workers, London, UK

- Characteristics and Risk Factors of Hospitalized and Nonhospitalized COVID-19 Patients, Atlanta, Georgia, USA, March-April 2020

- Improving Treatment and Outcomes for Melioidosis in Children, Northern Cambodia, 2009-2018

- Eastern Equine Encephalitis Virus in Mexican Wolf Pups at Zoo, Michigan, USA

- Genomic Analysis of Novel Poxvirus Brazilian Porcupinepox Virus, Brazil, 2019

- Highly Pathogenic Avian Influenza Clade 2.3.4.4 Subtype H5N6 Viruses Isolated from Wild Whooper Swans, Mongolia, 2020

- SARS-CoV-2 Seropositivity among US Marine Recruits Attending Basic Training, United States, Spring-Fall 2020 